\title{
st \\ Sir Karl Popper e o darwinismo
}

\author{
Marcelo Alves Ferreira
}

A imagem contemporânea da ciência tem aspectos problemáticos em vários campos, sobretudo quando se considera seu impacto sobre o público não especializado. Abusos da economia, da história e da biologia são freqüentes nos meios de comunicação, com conseqüências mais sérias do que podem parecer à primeira vista. Na última década, ganhou importância o debate sobre o ensino da teoria da evolução nas escolas públicas dos Estados Unidos e de outros países, inclusive o Brasil. O enfrentamento entre as posições evolucionistas e criacionistas chegou aos tribunais e aos poderes legislativos, ameaçando o ensino adequado da biologia, conforme entendida pela comunidade científica ou comprometendo o caráter laico do ensino público. Concepções grosseiramente simplificadas dos conteúdos de várias ciências têm contribuído para o apoio popular à posição criacionista, mas, infelizmente, posições que fazem parte do debate acadêmico especializado de temas da filosofia da ciência são instrumentalizadas no combate ao ensino da teoria da evolução. Proponentes do que às vezes se denomina "criacionismo científico" procuram promover o conceito de criação divina ao estatuto de ciência enquanto buscam caracterizar a teoria da evolução como crença ou ideologia, apropriando-se de críticas filosóficas de pensadores importantes, como Karl Popper (cf. Gish, 2005). Esse estado de coisas motiva a presente nota crítica, uma vez que a autoridade intelectual de Popper não pode ser ignorada nesse debate e suas críticas ao darwinismo devem ser compreendidas e contextualizadas para que não conduzam a mal-entendidos.

O problema da demarcação é um aspecto central da obra de Popper como filósofo da ciência. Seus critérios de cientificidade envolvendo conceitos como refutabilidade e poder preditivo de teorias são fundamentais para produzir uma separação razoavelmente clara entre o que é e o que não é ciência. Por razões históricas óbvias para uma teoria que se desenvolveu no período de 1930 a 1960, o marxismo e a teoria psicanalítica foram alvos freqüentes da crítica popperiana, no caso da psicanálise centrada na irrefutabilidade das teorias adlerianas, baseadas no complexo de inferioridade; no caso do marxismo, em função da recusa ideológica de seus aderentes em reconhecer instâncias de refutação de partes da teoria advindas da história recente. Também encontramos em Popper críticas ao darwinismo enquanto teoria científica. A atenção que 
Popper dedicou ao darwinismo não foi pouca, começando por The poverty of historicism (Popper, 1957) passando por várias conferências como, por exemplo, Evolution and the tree of knowledge $\mathbf{1}$ e atingindo algum detalhamento no livro Objective knowledge: an evolutionary approach (Popper, 1972) e sobretudo em Darwinism as a metaphysical research programme, parte de suaAutobiografia intelectual (Popper, 1974). É principalmente nesta última publicação que está baseada a presente análise.

O texto de Popper pode ser dividido em duas partes: uma avaliação do estatuto científico do darwinismo e uma série de sugestões teóricas do autor para aprimorar dois aspectos da teoria da evolução: a ortogênese e o valor da sobrevivência em termos de aptidões dos organismos. Nesta crítica as discussões se encontram na ordem oposta àquela em que Popper expôs suas idéias, talvez porque esposo uma apreciação diferente da importância relativa entre as partes.

\section{As sugestões de Popper Para APRimorar o DARWINismo}

É importante ressaltar, como ele mesmo o fez, que Popper elabora suas proposições teóricas sobre a evolução tendo como ponto de partida a biologia da segunda metade do século $\mathrm{xx}$, referindo-se pelo termo darwinismo (para maior brevidade) ao que se denomina mais precisamente "teoria sintética da evolução", "nova síntese" ou ainda "neodarwinismo". As contribuições teóricas que Popper oferece à teoria estão descritas de forma sucinta, mas muito clara, nas seis últimas páginas (p. 138-43) de Darwinism as a metaphysical research programme podendo ser enumeradas e resumidas como segue:

i. A distinção entre pressão seletiva interna (originada no próprio organismo, principalmente em suas "preferências e objetivos") e externa (originada pela totalidade do habitat).

ii. A suposição de diferentes tipos de genes, alguns responsáveis por traços anatômicos e outros por traços comportamentais, estes últimos subdivididos em genes das "preferências"”2 e das habilidades.

iii. O esquema de seleção natural, no qual os traços comportamentais dos animais e a variabilidade desses traços são estabelecidos por seleção em várias etapas distintas. Em um primeiro momento, diante de mudanças ambientais, um

1 Conferência dada como parte da Herbert Spencer Memorial Lecture em Oxford em 1961.

2 Popper usa os termos "preferência" e "comportamento" com a compreensão de que o primeiro é distinto e mais restrito que o segundo. Nos dois últimos parágrafos (p. 14,3) de Darwinism as a metaphysical research programme, ele afirma que sua ênfase em preferências leva obrigatoriamente ao estudo da emergência dos estados de consciência. 
organismo muda apenas seu comportamento, sem que haja mudança em seu genótipo. O novo comportamento poria o organismo em um novo nicho ecológico, fazendo com que o novo comportamento fosse fixado geneticamente, por seleção natural, uma vez que haveria desvantagens na regressão ao comportamento previamente prevalente. Em uma etapa posterior, esses eventos se configurariam em uma pressão seletiva interna que agiria sobre os genes das habilidades, que ulteriormente pressionariam pela seleção de mudanças anatômicas. O esquema contempla ainda a existência de retroalimentação de cada etapa pelas posteriores, de modo que as mudanças anatômicas reforçariam a seleção de habilidades adequadas às estruturas modificadas e estas habilidades adquiridas reforçariam os comportamentos que delas fizessem uso.

iv. A sugestão de que os itens anteriores oferecem uma solução para o problema da evolução em direção às formas de vida "superiores", ou seja, para uma das versões do problema da ortogênese, solução que, segundo Popper, o darwinismo teria falhado em oferecer. No esquema do item anterior, a seleção por etapas, (preferências $\rightarrow$ habilidades $\rightarrow$ anatomia), seria responsável pela aparição de formas de vida superiores, enquanto que o predomínio das retroalimentações dessas mesmas etapas levaria à estagnação, ou seja, a fixação genética de um comportamento reduziria a flexibilidade comportamental da espécie e comprometeria a continuidade a longo prazo desse mecanismo evolutivo.

v. A sugestão de que os itens $i$ a iii oferecem uma solução ao problema da especiação, sem que o isolamento geográfico seja um elemento obrigatório do processo. Esta questão ocupou os criadores da teoria sintética, pois a necessidade de isolamento geográfico de populações como requisito para a especiação resultava em uma deficiência teórica do darwinismo original. Em muitas situações, a proposição de isolamento geográfico acidental como fator do surgimento de uma nova espécie se assemelhava à interposição de uma hipótese $a d$ hoc. A idéia de que um comportamento possa estar geneticamente determinado é essencial para a aceitação de que barreiras não geográficas possam isolar reprodutivamente uma subpopulação e desencadear a formação de uma nova espécie.

vi. A descrição da seleção natural como seleção de características pelo seu "valor para a sobrevivência" é inapropriada e está relacionada com a teleologia. Popper propõe que os fatores adaptativos concretos envolvidos não são em si mesmos questões de sobrevivência, mas aspectos mais bem entendidos como de "solução de problemas". 
Os itens $i$ a $i v$ descrevem as sugestões de Popper quanto ao processo evolutivo chamado de ortogenético, ou seja, aquele processo que apresenta uma tendência ou direção aparente ao longo de uma série de transformações em uma linha filogenética. O item $v$ conecta esse problema ao da especiação. Quanto ao item vi, trata-se de uma interpretação da seleção natural altamente relevante para a discussão do estatuto do darwinismo, relevância que foi todavia ignorada no texto de Popper, o que não deve causar surpresa, considerando o teor da discussão do estatuto científico da teoria da evolução feita por ele.

Lamentavelmente a discussão das propostas de aprimoramento do darwinismo feitas por Popper tem que começar pela constrangedora constatação de que praticamente todas elas foram feitas tarde demais: os cientistas envolvidos na elaboração do neodarwinismo já haviam percorrido seu conteúdo (caso dos itens $i$, ii, iii e v), estando à frente de Popper. Outra característica de suas sugestões, que ele deixa de explicitar, é que sua validade restringe-se aos animais, com grande relevância apenas para os mais complexos, de comportamento mais flexível. Plantas e microorganismos parecem ter sido negligenciados, como freqüentemente se dá mesmo entre os teóricos darwinistas, apesar das tendências ortogenéticas e dos problemas de especiação serem tão importantes nesses organismos como em quaisquer outros.

A distinção proposta por Popper entre pressão seletiva interna e externa já havia sido proposta em textos clássicos do neodarwinismo, como os de Ernst Mayr (1960).

A idéia de que as características fenotípicas dos organismos, moldadas pelo seu comportamento, são também pressões seletivas já aparece sob o nome de seleção orgânica nos trabalhos de H. F. Osborn, J. M. Baldwin e C. Lloyd Morgan (cf. Bowler, 1989) na última década do século xix e primeira década do século xx. Popper chega a citar o "efeito Baldwin"3 em favor de sua sugestão, tornando impossível entender que nova idéia ele possa estar trazendo ao darwinismo.

Ao supor a existência de diferentes classes de genes que determinariam o comportamento, a habilidade e a anatomia, Popper concede que existam genes com função mista, um fenômeno estabelecido décadas antes com o nome de pleiotropia e mencionado no clássico Genetics and the origin of species (Dobzhansky, 1937). Ele todavia opta explicitamente por deixar esses genes fora de suas considerações, incorrendo em uma simplificação apriorística grave.

A proposta de que a seleção por etapas conforme a seqüência citada em iv é uma solução para o problema da ortogênese e do aparecimento de formas de vida superio- 
res deixa claro que Popper se refere à presença de tendências em linhagens evolutivas, especialmente à presença de tendências de aumento de complexidade. Surge aí uma questão: as tendências só se constituem em um problema se excluirmos a possibilidade de que elas já estejam presentes no próprio processo de seleção natural, o que parece ser o caso de Popper.

Em Darwinism as a metaphysical research programme, ele afirma que "a teoria prediz mutações acidentais e, portanto, mudanças acidentais". Ainda que a afirmação seja correta no caso de organismos individuais, quando se trata de populações, a idéia central do darwinismo é totalmente diversa desse raciocínio, segundo o qual o acaso sempre gerará acaso. A seleção natural transforma mudanças individuais ao acaso em mudanças populacionais com sentido adaptativo, tanto pela eliminação dos indivíduos com mudanças desfavoráveis como pela promoção reprodutiva daqueles com mudanças favoráveis. Parece-me que esse é precisamente o sentido do termo seleção natural, sua não casualidade, sua seletividade intrínseca. As mutações e a variação decorrente são não direcionais, mas a fixação delas ao longo das gerações em uma determinada população, ou mesmo em uma espécie inteira, são necessariamente dirigidas pelas características do ambiente. Mutações podem alterar a taxa de crescimento de uma planta para mais ou para menos em variados graus, mas, depois de várias gerações, a população reterá as mudanças que forem condizentes com a disponibilidade de luz, de nutrientes no solo, de oportunidades de dispersão de sementes e assim por diante. Ao afirmar que a descrição darwinista acarretaria seqüências evolutivas do tipo "caminhada ao acaso" (random walk no original), Popper ignora que as mudanças do ambiente podem ter, por períodos geologicamente significativos, um sentido consistente, o que tem sido comprovado, por exemplo, em estudos paleoclimáticos. Esse conceito de seleção direcional por períodos apreciáveis acarretando seqüências evolutivas com tendências identificáveis foi proposto em 1903 por Ludwig Plate ${ }^{4}$ com o nome de ortoseleção (cf. Mayr, 1982).

Novamente, no caso do item $v$, ao propor seu mecanismo de seleção por etapas (com mudanças no comportamento antecedendo as mudanças estruturais) como explicação para a especiação por isolamento reprodutivo não geográfico, Popper apenas repete Dobzhansky, que propôs o mecanismo "sexual ou psicológico” de isolamento (cf. Dobzhansky, 1937).

Embora as considerações feitas até agora acerca das contribuições teóricas de Popper possam fazer parecer que elas sejam todas desnecessárias ou equivocadas, na última que enumerei, item vi, há o germe de algo valioso para o debate filosófico sobre 
o darwinismo, algo que curiosamente entra em contradição com o julgamento que Popper faz do estatuto do darwinismo e do qual tratarei na segunda parte desta crítica. O autor nos diz que as idéias de "valor de sobrevivência" e de teleologia podem ser clarificadas, se forem entendidas em termos de "solução de problemas". O mais importante na interpretação proposta por Popper é explicitar que o valor de sobrevivência não se reduz tautologicamente a sobreviver, mas, em suas palavras: “Todo organismo e toda espécie encara constantemente a ameaça da extinção; mas essa ameaça toma a forma de problemas concretos que ele tem que resolver" (Popper, 1974, p. 142; grifo meu).

Ele propõe que muitos problemas surgem sob pressões seletivas externas, mas sempre em conjunto com os prexistentes instintos e preferências dos organismos, o que é compreensível apenas no contexto de seres vivos concretos. Estranhamente, Popper afirma que os problemas enfrentados por indivíduos para, digamos, se reproduzirem não afetariam em muito a espécie a que pertencem, mas desenvolve a noção interessantíssima de que a evolução seria uma realidade emergente e irredutível das entidades biológicas, descritível em termos físico-químicos, mas nunca explicável nesses termos.

Mais adiante ele afirma que esses problemas dos organismos “[...] são realidades biológicas específicas; eles são 'reais' no sentido em que sua existência pode ser a causa de efeitos biológicos" (Popper, 1974, p. 143). É extremamente difícil compreender essas afirmações sobre o "valor de sobrevivência" como fazendo referência a hipóteses não testáveis. $\mathrm{O}$ autor fala de problemas reais, que seriam causas físicas de fenômenos biológicos. Em que sentido então o termo metafísico se aplicaria ao darwinismo?

\section{O estatuto do DARwinismo Segundo Popper}

Popper afirma em Darwinism as a metaphysical research programme que o darwinismo não é propriamente testável, sendo por essa razão metafísico. Um positivista lógico, caso chegasse a qualificá-lo como metafísico, extrairia como conseqüência que as idéias de Darwin não fazem sentido. Popper crê que elas fazem sentido, e as considera valiosíssimas como uma "possível estrutura para teorias testáveis". Ele usa o termo metafísico em outro sentido, no que foi seguido por Lakatos. Ao usar o termo programa de pesquisa metafísico, Popper toma novamente para si esse conceito de metafísica. O fundamental nesse conceito especial de metafísica é o reconhecimento de que, ainda que com caráter convencionalista ou puramente metodológico, a ciência precisa admitir premissas especulativas não testáveis para ser uma atividade possível. $\mathrm{O}$ autor alinha o darwinismo com o dedutivismo, a seleção e a eliminação crítica de erros em oposição ao lamarckismo que se alinharia, respectivamente ao indutivismo, à instrução por re- 
petição e à justificação. Tendo em vista as características formais do método científico, tal como visto por Popper, diríamos que, no exposto acima, ele aprova implicitamente o darwinismo de modo bem forte. Nesse ponto, Popper revela o vigor de seu empirismo ao ressaltar a força lógica do darwinismo negando-lhe simultaneamente o estatuto de teoria científica testável pela experiência. Segundo Lakatos,

A metodologia de um programa de pesquisa com um núcleo "metafísico" não difere da metodologia de um programa de pesquisa com um núcleo "refutável", exceto, talvez, no que concerne ao nível lógico das incoerências que são a força condutora do programa (Lakatos, 1979, p. 155).

Como Popper nos mostra que o darwinismo não é testável? Por dois argumentos distintos mas fortemente interligados, o primeiro se refere ao poder explicativo da teoria ante um fenômeno biológico geral (a geração de grande diversidade de espécies ao longo do processo evolutivo na Terra) e o segundo se refere à descrição do mecanismo pelo qual a evolução se daria, de acordo com a teoria de Darwin.

No primeiro caso, Popper pergunta se o darwinismo seria refutado caso encontrássemos em Marte apenas três espécies de bactérias, em contraste com a grande variedade de vida que vemos na Terra. A resposta é negativa; disso, ele conclui que a teoria explicaria tão poucas espécies pelos mesmos mecanismos com que explica a variedade, ou seja, a teoria na verdade não prediz a variedade e, portanto, não a pode explicar. $\mathrm{O}$ exemplo hipotético de vida em Marte poderia ser reconstruído de modo a prever descobertas que, estas sim, refutariam o darwinismo, além de outras considerações sobre as causas da diversidade na Terra que poderiam torná-lo refutável em um sentido popperiano, como aponta Ruse (cf. Ruse, 1977). Podemos ainda objetar que há outras formas pelas quais o darwinismo seria refutado aqui mesmo na Terra. A descoberta, logicamente pensável, de fósseis humanos mais antigos que qualquer fóssil de mamífero, digamos que datado em 4,00 milhões de anos, refutaria boa parte do darwinismo. Outros achados inconsistentes com as árvores filogenéticas também podem ser razoavelmente imaginados. A despeito desses contrapontos, creio que esta crítica acerca da explicação da diversidade seja a mais conseqüente de todas as apresentadas por Popper. A quantificação da diversidade é algo que a teoria evolucionista ainda não alcança de forma apreciável, ou seja, a teoria propõe que haja uma relação de descendência entre as muitas formas de vida que encontramos hoje e as poucas (talvez apenas uma) que existiam no começo do processo, mas ela não nos diz com nenhum grau apreciável de precisão quantas espécies devemos encontrar em determinadas épocas e ambientes.

No segundo caso, Karl Popper adere à linhagem de críticos do darwinismo que inclui Manser, Macbeth e Bethel, argumentando em torno do que seria o caráter quase 
tautológico da teoria. É nesse ponto que chego às conseqüências contraditórias da sugestão final (vi) das contribuições de Karl Popper ao darwinismo, aquela na qual o valor de sobrevivência é substituído pela solução de problemas, evitando a conexão com a teleologia, ou seja, o objetivo intrínseco de sobrevivência. Ao sugerir esse novo ponto de vista, o filósofo esbarra, por assim dizer, na negação do caráter metafísico do darwinismo. Nesse segundo argumento, Popper afirma basicamente que é quase tautológico dizer-se que uma espécie viva está adaptada a seu ambiente e que outra extinta se extinguiu por não estar (cf. Popper, 1974, p. 137). Além disso, ele nos diz que a teoria moderna define adaptação em termos de sobrevivência.

$\mathrm{Na}$ verdade, a teoria afirma que as características específicas dos indivíduos definidas pelas características do ambiente afetam probabilisticamente sua sobrevivência e reprodução de modo sistemático. Reprodução diferencial (a não sobrevivência de toda a descendência) e a existência de variações nas populações são dados observacionais. $\mathrm{O}$ fato de dificuldades técnicas terem mantido muitas hipóteses nesse sentido como não testadas pela experiência não as faz não testáveis em princípio. Essas hipóteses são riquíssimas em conteúdo empírico e de forma alguma se restringem à "sobrevivência dos que sobrevivem". As probabilidades de sobrevivência é que contam, e são probabilidades de subpopulações previamente definidas em termos anatômicos, fisiológicos ou etológicos, e não em termos de mera sobrevivência ou sucesso reprodutivo. A aplicação estrita que Popper faz de suas proposições normativas acerca do desenvolvimento científico o faz igualar perigosamente o não refutado ao não refutável no caso do darwinismo.

Creio que a relação de contradição entre o que enumerei como item vi das sugestões de Popper e seu argumento da quase tautologia se torna clara: ao propor que o valor de sobrevivência deve ser analisado como capacidade de solução de problemas concretos, o autor indiretamente concede que a adaptação seja testável em outros termos, como "[...] causas de efeitos biológicos" e não apenas como sobrevivência post facto.

Se o filósofo indiretamente concede que a seleção natural, vista como solução de problemas, é, em princípio, um hipótese testável, o que restaria como núcleo irredutível ou metafísico do darwinismo? Há pouca disputa na comunidade científica quanto ao que seja o núcleo da teoria da evolução: a seleção natural é esse núcleo. O que gera controvérsias férteis e produtivas entre os teóricos da evolução é a discussão da importância que podem ter os outros elementos envolvidos no processo e que nível de independência eles podem ter em relação à seleção natural. A deriva genética, os modos de especiação, o peso da embriogênese como limitante da seleção, o quanto a seleção passada pode condicionar os efeitos da seleção presente e outros temas são a arena do debate contemporâneo, mas esse debate não aponta para um deslocamento do núcleo da teoria, ele aponta para uma expansão da sua periferia. 
Em entrevista a John Horgan em 1992, Karl Popper declarou sobre sua qualificação do darwinismo como sendo metafísico e tautológico que: "Isso talvez tenha sido exagerado". E ainda: "Não sou dogmático a respeito de minhas próprias opiniões" (Popper, apud Horgan, 1998, p. 55).

É sem dúvida uma retratação tímida, mas merece ser lida por muitos admiradores de Popper que partilharam de suas reservas ao neodarwinismo. São muitos os significados que podemos atribuir ao termo exagerado na frase de Popper, além dos outros excessos por ele cometidos em sua discussão da evolução. Para manter o foco no essencial, espero que a presente crítica tenha estabelecido algumas diferenças entre o neodarwinismo e o neodarwinismo sob os olhos de Karl Popper.

Enquanto para Popper "dizer que uma espécie atualmente viva está adaptada ao seu ambiente é, de fato, quase tautológico" (1974, p. 137), a teoria da evolução, de sua parte, afirma que uma espécie atualmente viva está quase adaptada, o que não é nada tautológico.

A incorporação das críticas popperianas ao discurso criacionista pode e deve ser rejeitada no debate atual sobre o ensino da teoria da evolução sem que a maioria dos elementos desta nota crítica seja considerada. O discurso criacionista procura apropriar-se da autoridade intelectual de Karl Popper com o intuito de desacreditar a teoria da evolução enquanto teoria científica. Essa posição ignora a complexidade da discussão feita por Popper, a qual procuramos expor criticamente nesta nota. Em nenhum momento de sua discussão, Popper exclui a teoria da evolução do campo da ciência. Embora considerando sua crítica inválida em muitos pontos, mesmo que a assumíssemos in totum, o darwinismo subsistiria como um programa de pesquisa inestimável, segundo o próprio Popper.

Além do fato de que as críticas popperianas podem ser questionadas e de que, mesmo que não o fossem, o darwinismo subsistiria, há outro motivo pelo qual a incorporação criacionista da crítica popperiana é insustentável. A crítica do autor à teoria não questiona os dados advindos da paleontologia de que houve uma vasta transformação dos seres vivos ao longo da história da Terra. Popper questiona o quanto o darwinismo é capaz de explicar esse fenômeno, mas não questiona a existência do fenômeno e nem admite a explicação teísta da adaptação, pois a considerava pior que qualquer admissão de fracasso, uma vez que o teísmo criaria a falsa impressão de que uma explicação foi alcançada.

Marcelo Alves Ferreira Biólogo, pós-graduando do Departamento de Filosofia, Universidade de São Paulo. piktor67@yahoo.com.br 


\section{REFERÊNGIAS BIBLIOGRÁFICAS}

Bowler, P. J. Evolution: the history of an idea. Berkeley, University of California Press, 1989.

Dobzhansky, T. Genetics and the origin of species. New York, Columbia University Press, 1937.

Gish, D. The nature of science and of theories on origins. Diponível em: $<$ http://www.icr.org/pubs/imp/imp262.htm> Acesso em: 18 mar. 2005.

Horgan, J. O fim da ciência: uma discussão sobre os limites do conhecimento científico. São Paulo, Companhia das Letras, 1998.

LAKATOS, I. O falseamento e a metodologia dos programas de pesquisa científica. In: \& Musgrave, A. (Org.). A crítica e o desenvolvimento do conhecimento. São Paulo, Cultrix / EDUSP, 1979. p. 109-24,3. \& Musgrave, A. (Org.). A crítica e o desenvolvimento do conhecimento. São Paulo, Cultrix/EDUSP, 1979.

MaYr, E. The emergence of evolutionary novelties. In: TAx, S. (Ed.). Evolution after Darwin, Chicago, University of Chicago Press, 1960. p. 349-80.

The growth of biological thought. Cambridge, Harvard University Press, 1982.

Popper, K. The poverty of historicism. London, Routledge and Kegan Paul, 1957.

. Objective knowledge: an evolutionary approach. Oxford, Oxford University Press, 1972.

Darwinism as a metaphysical research programme. In: Schilpp, P. A. (Ed.). The philosophy of Karl Popper. La Salle, Open Court, 1974. v. 1, p. 133-433.

Ruse, M. Karl Popper's philosophy of biology. Philosophy of Science, 44, p. 638-61, 1977.

Schilpp, P. A. (Ed.). The philosophy of Karl Popper. La Salle, Open Court, 1974. 2v.

TAx, S. (Ed.). Evolution after Darwin. Chicago, University of Chicago Press, 1960. 